\title{
Global Supply Chain Management at Digital Equipment Corporation
}

BRUCE C. ARntZEN

GerALD G. BROWN

TERRY P. HARRISON

LiNDA L. TRAFTON
Systems Manufacturing and Logistics Group Digital Equipment Corporation

129 Parker St., PK02-1//30

Maynard, Massachusetts 01754

Operations Research $(\mathrm{OR} / \mathrm{BW})$

Naval Postgraduate School

Monterey, California 93943

Management Science Department

Penn State University

University Park, Pennsylvania 16802

Worldwide Manufacturing and Logistics Digital

Equipment Corporation

Amherst, New Hampshire 03031

Digital Equipment Corporation evaluates global supply chain alternatives and determines worldwide manufacturing and distribution strategy, using the Global Supply Chain Model (GSCM) which recommends a production, distribution, and vendor network. GSCM minimizes cost or weighted cumulative production and distribution times or both subject to meeting estimated demand and restrictions on local content, offset trade, and joint capacity for multiple products, echelons, and time periods. Cost factors include fixed and variable production charges, inventory charges, distribution expenses via multiple modes, taxes, duties, and duty drawback. GSCM is a large mixed-integer linear program that incorporates a global, multiproduct bill of materials for supply chains with arbitrary echelon structure and a comprehensive model of integrated global manufacturing and distribution decisions. The supply chain restructuring has saved over $\$ 100$ million (US).

Untwisting all the chains that tie The hidden soul of harmony.

-Milton, L'Allegro

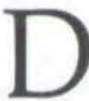
igital Equipment Corporation is the world's third-largest vertically inte-

Copyright \& 1995, Institute for Operations Research and the Management Sciences

$0091-2102 / 95 / 2501 / 0069501.25$ grated computer company. In 1991, Digital (DEC) served one quarter-million customer sites, with more than half of its $\$ 14$ billion revenues coming from 81 countries outside the United States, principally

INVENTORY/PRODUCTION-MULTI-ITEM/ECHELON/STAGH PRODUCTION/SCHEDULING-PLANNING INTEGER PROGRAMMING-APPLCATIONS 


\section{Europe.}

The stock market crash of October 19 , 1987 and the subsequent market turmoil in 1990-1991, along with rapid changes in computer and communications technology, created a substantial change in demand for large computers that the largest computer manufacturers had not foreseen [Dyson 1992]: networks of smaller, less expensive computers could now replace central mainframes.

In his first public appearance after becoming Digital's new president and chief executive officer, Robert Palmer summed up his prescription for a $\$ 14$ billion company that had just lost $\$ 3$ billion [Electronic Business 1992, p. 121]:

"DEC is going to change. . . The historically high margins on hardware and the business model upon which Digital was built are no longer sustainable."

Digital needed to reshape its operations, to set the pace, rather than just keep up with the rapid improvements in technology, the semiconductor price-performance ratio, and shortened product manufacturing times. Digital needed to reinvent itself, and quickly.

\section{The View from Digital}

In 1987, Digital supported a full range of products with heavy reliance on minicomputers and mainframes containing many large complex modules. The company was also vertically integrated to produce chips, printed wire boards, memory, thin film magnetics, disks, power supplies, cabinets, cables, keyboards, modules (printed wire boards populated with components), kernels (the enclosure containing modules, processor, power supply, disks, and so forth), and finished computers. Almost ev- ery major component was built at Digital. Physically this included 33 plants in 13 countries, with distribution and service supplied via 30 distribution and repair centers.

This structure had proven to be very successful for over 20 years. However, the market changed. Increasingly, customers favored networks of simple, low-margin personal computers (PCs) and workstations with powerful microprocessors. This change left many manufacturers, including Digital, with a mismatch among capacity and infrastructure and demands of the new markets.

Between the fall of 1988 and summer of 1993, Digital made wholesale changes to both its physical and organizational structure to survive in this new environment. The demand for high-end and mid-range systems and for large complex modules had shrunk and been replaced by the need to build several times as many PCs, which require less space and fewer resources. In addition, Digital changed its strategy of high vertical integration and eventually focused on several core technologies and competencies. It stopped manufacturing power supplies, cables, printed wire boards, and keyboards. Although there was rapid growth in portions of the supply chain that Digital retained, for example, semiconductors, modules, and systems, the overall effect of the new sourcing strategy was a decreased requirement for manufacturing space and capacity.

Similarly, Digital's logistics systems, networks, and practices have been designed to consolidate and deliver a moderate number of complex (multi-box) orders for large computer systems. Now it must de- 
liver a huge number of desktop PCs and workstations rapidly and reliably.

The decision-making process for determining plant charters and allocating the changing load became strained. Lacking facts, trade-offs, and sensitivity analysis, Digital needed to streamline its decisionmaking process. As business decreased, Digital required less infrastructure both physically (too many plants) and organizationally (too much overhead). Product business units, geographic regions, and corporate groups competed for control of sourcing and capacity planning. Each had "decision-making forums and processes" whose purview overlapped the others. Plants submitted bids to all three forums and lobbied each for manufacturing load. The decision making process had to be reinvented.

In early 1989 , Digital began redesigning its supply chain by rationalizing its supply and delivery network and by reengineering the business processes throughout manufacturing and logistics. It needed a corporate sourcing and capacity planning process that included modeling tools, dedicated analytical resources, and decision-making criteria. The product business units and Corporate Logistics and Manufacturing initiated development of the Global Supply Chain Model (Appendix A). GSCM was to simultaneously balance the multiple, conflicting attributes of manufacturing and distribution: time, cost, and capacity. The goal was an unbiased and fact-based decision-making tool for supply chain stakeholders.

\section{The Need for Supply Chain Modeling at Digital}

Digital, like any firm that manufactures, distributes, and services its products worldwide, needs global supply chain management and modeling. Such firms need to consider many things when designing their supply chains:

- The location of customers and suppliers,

- The location and availability of inexpensive skilled labor,

- The length of the material pipeline in distance and time,

- The transit time and cost of various transportation modes,

- The significance and location of tax havens,

- Offset trade (value of goods and services purchased in a country to balance the sale of products in that country) and local content targets (percentage of components, by value, for a product), and -Export regulations, duty rates, and drawback policies.

Multinational manufacturing firms constantly question the design of their supply chains (Figure 1). The answers are typically not obvious and require understanding the trade-offs between many conflicting factors.

In setting a global supply strategy for manufacturing, they must decide

- How many plants they need, where to locate them, and what technologies and capacities each should have;

-What degree of vertical integration is best;

- Should a product be built at one plant, two plants, or three, and at what volumes do the answers change; and -Are tax havens worth the extra freight and duty.

In designing a global logistics network, they must decide 


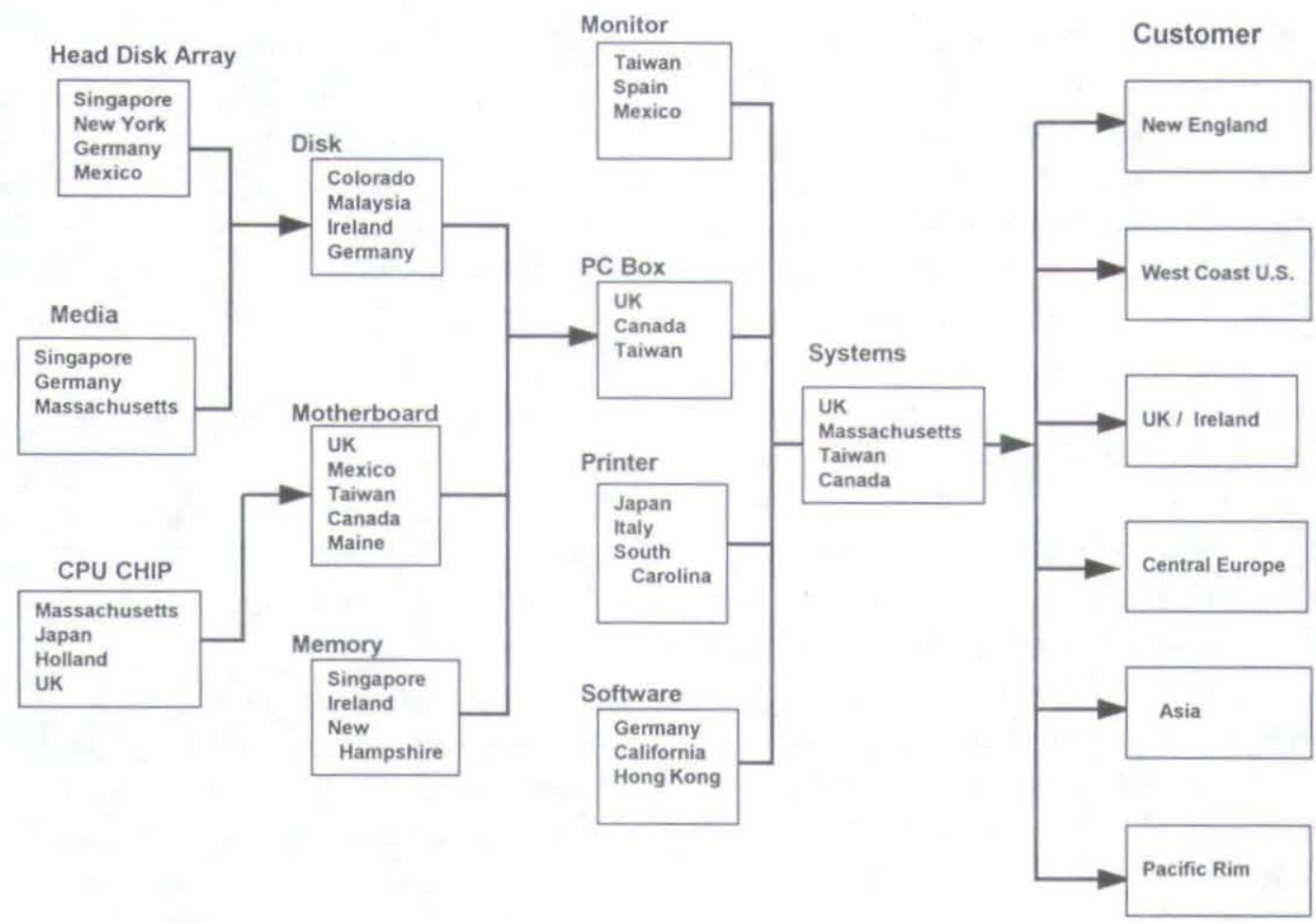

Figure 1: In a typical (hypothetical) global supply chain for the fabrication of a personal computer, component products may be manufactured by more than one alternate facility, then shipped to other facilities, and perhaps returned later in more completed form for additional fabrication. The global supply chain model represents the fabrication stages, locations, and recipes as a global bill of materials, while the entire figure, less the unused locations, depicts a global supply chain. Despite the left-to-right stages shown, the traditional paradigm of "echelons" for production and distribution does not apply to these supply chains.

- How many distribution centers there should be, where they should be located, and what methods of distribution and capacity each should have; and

-Which distribution centers should serve which customers for each type of order and product.

In designing a new product pipeline, they must decide

-What design provides the best balance between total cost and cumulative manufacturing and distribution time; and - How alternate volume forecasts affect unit costs and the choice of plants and suppliers.

In designing a worldwide supply (vendor) base, they must decide

-If they want to reduce the number of suppliers, and if so, which to keep; and -Which suppliers should supply each plant for each class of parts.

In designing a global network for spare parts and repair, they must decide

-What design is optimal for shipping spare parts between plants, vendors and customers; and

- How many repair centers there should be and which products should each repair. 
They must also set targets for offset trade and local content, deciding

-Which products they should manufacture or buy in a given nation to satisfy their offset trade requirement; and - How much extra it will cost or how much longer it will take to buy a product in a given nation.

These questions have guided our development of GSCM. With more changes in the computer industry, the advent of NAFTA (North American Free Trade Agreement), and the recent progress in the GATT (General Agreement on Trade and Tariffs), these questions are as compelling today as they were at the beginning of the project, in 1989.

\section{Prior Work on Managing Supply Chains}

Supply chain management is integrative, and thus it is no surprise that it has attracted the attention of a variety of business and academic disciplines.

In a thoughtful piece on the merits and future of Japanese, European, and American economic contests, Thurow [1992] predicts that, "New product technologies become secondary; new process technologies become primary." He feels that the deciding advantage will not come from superior resources, capital, or technology, but from the skills with which they are globally integrated and employed.

Cooper and Ellram [1993], logisticians, give an integrative introduction to establishing and managing a global supply chain.

Geoffrion and Graves [1974] introduce a multicommodity logistics network design model for optimizing annualized finishedproduct flows from factories and vendors via distribution centers to sole-sourced cus- tomers. Their Benders decomposition procedure finds optimal distribution center configurations while expressing much logistic detail with transportation and binary sourcing variables numbering into the millions. Geoffrion and Powers [1993] discuss many continued applications of this model and the global issues addressed in diverse industries and report that descendants of the original model accommodate more echelons and cross-commodity detail.

Breitman and Lucas [1987, p. 94] describe their decision support system as "a flexible framework for scenario description and analysis. . . . to decide what products to produce; when, where, and how to make these products; which markets to pursue; and which resources to use." These are probably common features with GSCM, considering their ambitious list of target issues and the wide array of applications described at General Motors, and considering that some kind of optimization is employed. However, the paper contains no details about the underlying mathematical models or software.

A succession of related papers begins with Cohen and Lee [1985], who introduced a pair of models: one for multicommodity manufacturing network design of annualized product flows from raw material vendors, via intermediate and final product plant echelons, distribution centers, and then to customers; the other a nonlinear model concentrating on production scale economies. They give no details about the underlying software and only offer that the network-design model is based on that of Geoffrion and Graves but is solved with heuristics.

Cohen and Lee [1988, p. 216] continue 
with a set of approximate stochastic submodels and heuristic solution methods for "linking decisions and performance throughout the material-production-distribution supply chain." Their aim is determining stationary long-term operational policy, rather than strategic design.

Next, Cohen and Lee [1989, p. 81] introduce a deterministic model much in the spirit of GSCM for "a global manufacturing and distribution network." They model an "international, value-added supply chain," and offer some anecdotal case studies for a personal computer manufacturer. Their model is informally defined to include value markups as well as costs, enabling estimation of before-tax and aftertax profitability, including exchange effects to a numeraire currency. They give local offset requirements as an interval for the value-added ratio about the after-tax profit ratio. In contrast to the work reported here, their "duties and tariffs are based on material flows." In stark contrast to GSCM, their implementation is in GAMS / MINOS [Brooke, Kendrick, and Meeraus

\section{Networks of smaller, less expensive computers could replace central mainframes.}

1988], which has no integer programming capability. Consequently, they solve only the continuous portions of their models, prespecifying "alternate sets of integer decision variables." They do not capture multiperiod effects directly, suggesting rather that these be handled by sequential model runs.

Finally, Cohen and Moon [1991] return to production with scale economies and introduce a mixed-integer linear program for plant loading.

Davis [1993] argues for complete global supply chain analysis from raw materials to finished products, with special emphasis on the "plague" of uncertainty at all levels. He includes case studies from HewlettPackard. The paper contains only a few hints of the mathematical approach, and no detail of underlying software. Thus, we can only surmise that the stochastic modeling is principally descriptive, that it is limited to analysis of the supply chain of one finished product at a time, and that the applications are more tactical than strategic.

\section{Model Design}

Any large supply chain that includes many products, technologies, customers, suppliers, plants, and logistics centers and that spans multiple countries is viewed differently by planners at various locations (Figure 2). The technology group sees a set of plants, each with a collection of skills and equipment to support different manufacturing processes. The sales force sees a set of customers, some of which have a plant that assists with marketing. Product managers see a set of resources to be quickly assembled to place new products on the market ahead of the competition.

We adopted a strategic view from manufacturing and logistics - that a supply chain is a set of facilities, technologies, suppliers, customers, products, and methods of distribution. Operation of the supply chain expends cost and time while resulting in various performance results. Beginning with a bill of materials, then adding candidate suppliers, facilities, costs, 


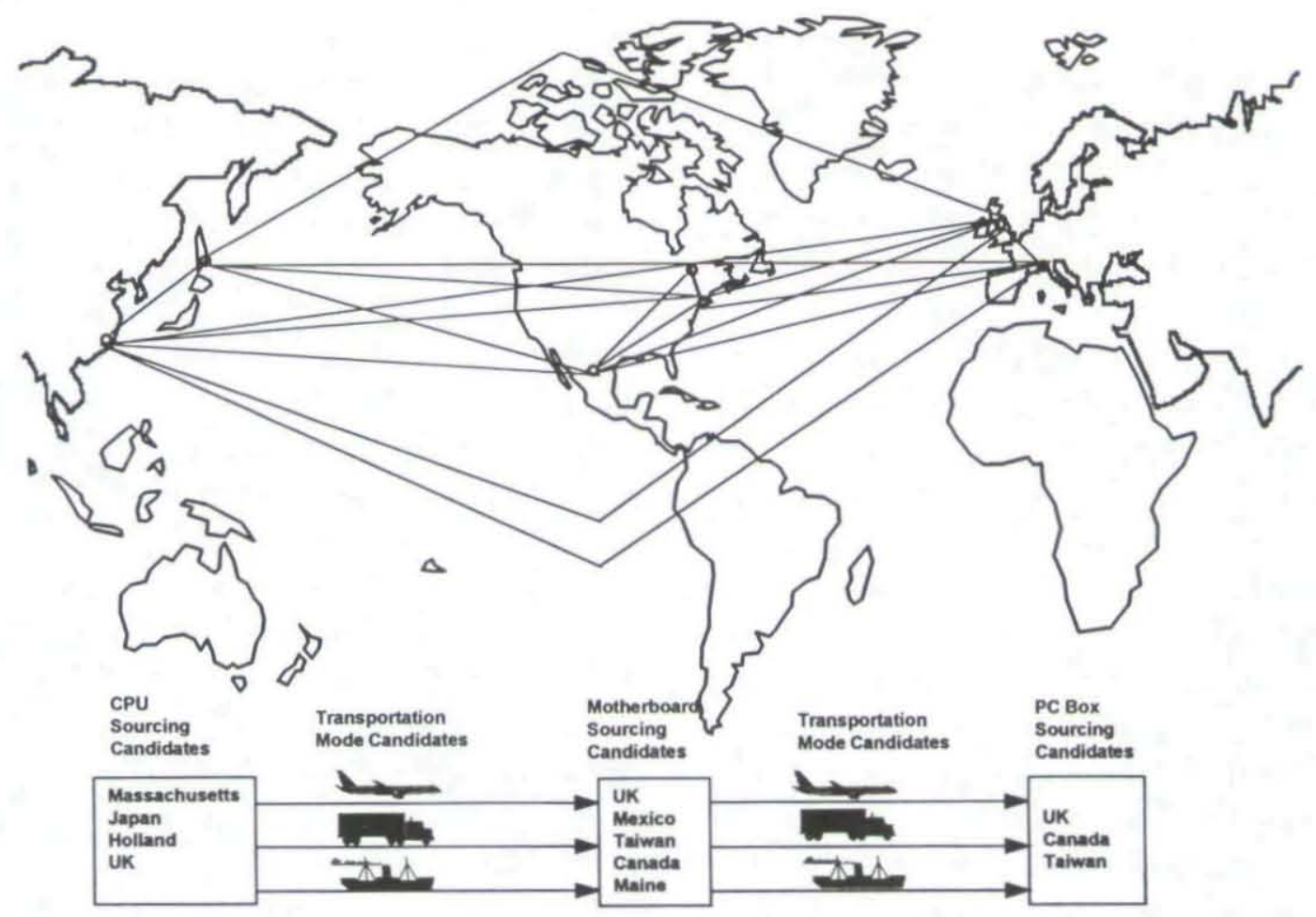

Figure 2: Global supply chains are complex. Even a few products can share among them hundreds of alternate chains of manufacturing and distribution links and modes. Each mode of transport inflicts a cost and a time delay, with cost and time dependent on the shipment sizes and frequencies.

and times, the sourcing and capacity planning group helps businesses transform their data into a network representation that can be modeled by GSCM.

Key Features of GSCM and Its Software Implementation

GSCM has evolved over four years from an original design which was much more modest than the current model. For example, we originally developed GSCM to consider only a single product, ignore duties, and to include only one type of fixed costs.

Currently, GSCM expresses global supply chain problems that include multiple products, facilities, production stages, tech- nologies, time periods, and transportation modes. It can also balance cost with time, while considering the global issues of duty and duty relief, local content, and offset trade. This type of model is particularly useful when a firm faces extremely short product life cycles and rapid technological change - situations in which simple, longterm stationary policies are inapplicable. GSCM is well suited for rapid deployment analysis.

Within GSCM, there are multiple measures of time. Cycle time is the length of the longest possible path through the selected production and distribution network to make and ship an individual product 
from start to finish.

Because including cycle time directly in an optimization model complicates things more than warranted here (the resulting problems are known as network design problems), we adopted another measure of time-weighted activity time. The activity time of a single link in the supply chain is the amount of time it takes to perform an individual operation in production or distribution. However, while cycle time is defined as the longest production and distribution path through the network, weighted activity time is the sum of processing times for each individual segment multiplied by the number of units processed or shipped through the link. This includes all segments with production or distribution activity, not just those on the longest path. GSCM uses weighted activity time in the objective function, although it also reports cycle time.

\section{Modeling Duty Drawback and Duty Avoidance}

The issues of modeling duties and recoveries of duties have not been well explored in the literature. When a product is imported into a nation, that nation may charge an import tax, or duty. Some nations have formed trading groups, which we call nation groups, within which products move duty-free. Each nation within a nation group charges uniform import duties to nations outside the group. The European Union (EU) and the nations signing the North American Free Trade Agreement (NAFTA) are examples of nation groups.

Duties, offset trade regulations, local content regulations, export regulations, and international tax considerations can form a real barrier to firms engaging in international trade. These issues are often handled by duty specialists within the firm. If these specialists operate independently from each other and from the primary functional areas, they may miss opportunities to coordinate their efforts with manufacturing and distribution decisions.

One of the typical responsibilities of the specialists is to advise manufacturing and logistics about the impacts of duties on various supply chain decisions. These specialists typically make recommendations on how to avoid incurring duties. The specialists' second responsibility is to track all imports and exports and capture any opportunities for duty drawback. Rarely does this group communicate early and fully enough with product-design and sourcing so that the original design of the supply chain accounts for these duty effects.

GSCM directly accommodates these duty considerations as part of the overall supply chain design (Appendix A). Although duties range from zero to 200 percent of the value of the product being imported, typical duty rates are five to 10 percent of the product value, which can easily amount to tens of millions of dollars. Duty drawback or duty avoidance options should always be considered.

There are three ways to avoid or draw back duty charges:

(1) A firm (say, in the United States) may import a product and subsequently reexport it (without change), claiming duty drawback for reexport in same condition;

(2) A firm may import a product, add value by using it to make a subassembly, and then export the subassembly, claiming 
duty drawback for reexport in a different condition; and

(3) A firm may export a product and later reimport it as part of a larger assembly, claiming duty avoidance for domestic goods returned in a different condition (but only on the product originally exported) (Figure 3).

\section{Model Description}

GSCM minimizes a weighted combination of total cost and activity days where total cost includes production costs, inventory costs, facility material handling costs, taxes, facility fixed charges, production line fixed costs, transportation costs, fixed costs associated with a particular method of manufacturing, and duty costs less duty drawback and duty avoidance.

This is subject to the following constraints:

- Customer demand is met for each product, in each time period, in each customer region;

- Production and inventory volumes are accounted for;

- Products are made using component

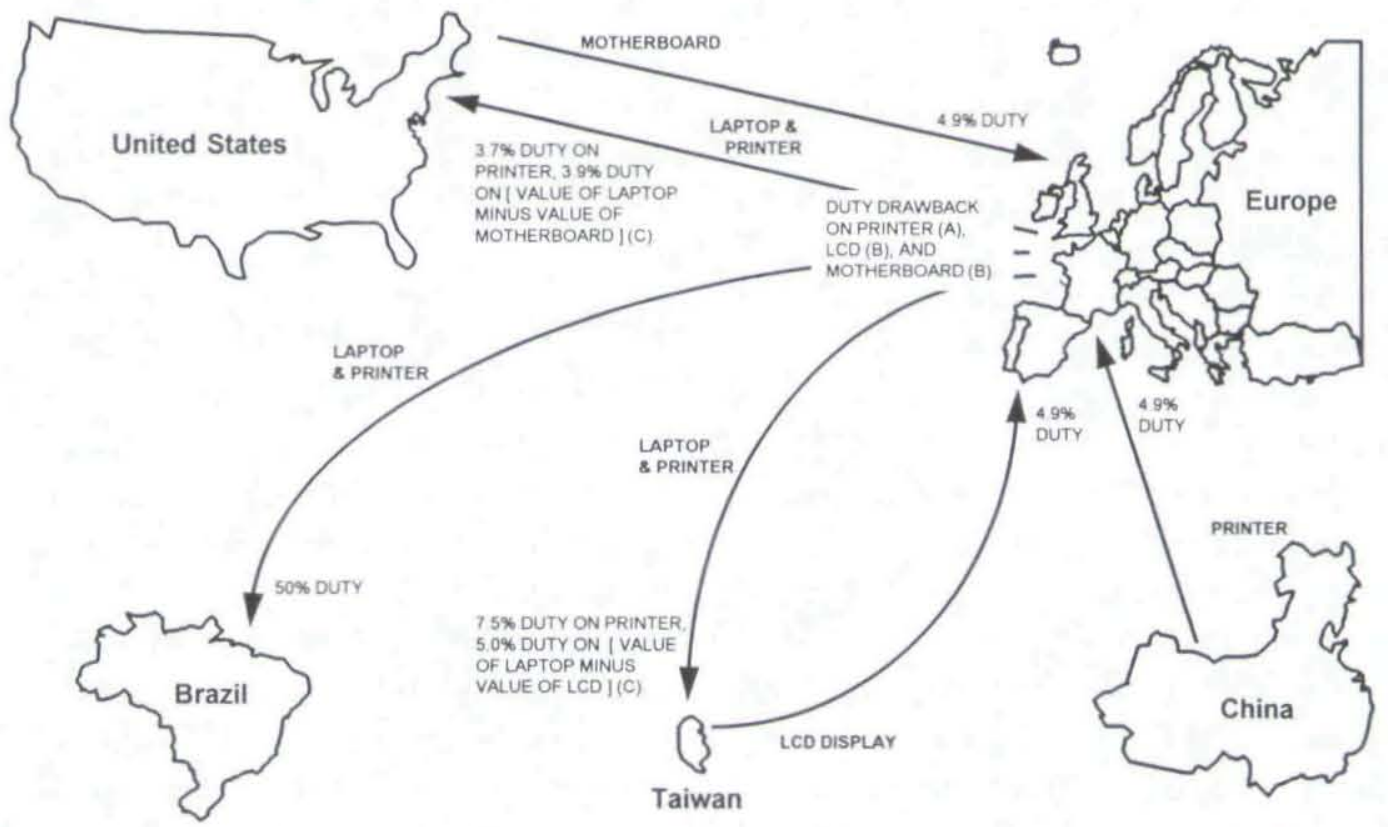

Figure 3: Duty drawback and duty avoidance are worth modeling. Shown are three ways to take advantage of import duty relief. When printers imported from China enter Europe, a duty of 4.9 percent is due. Europe also imports LCD displays from Taiwan and motherboards from the US to manufacture laptop PCs which it exports to Taiwan and the US. Laptop PCs with printers are exported from the US to Brazil. Because the printers from China went through Europe and were ultimately shipped to Brazil, they are eligible for European duty drawback for reexport in the same condition. Usually the same printers imported into Europe from China need not be reexported to Brazil; they need only be fungible, that is, equivalent. Europe imports LCDs from Taiwan, then reexports them to Taiwan in laptop computers. It avoids the 4.9 percent LCD duty due in Europe because of reexport in a different condition. The LCDs reimported into Taiwan also create an opportunity for duty avoidance for domestic goods returned in different condition. 
recipes;

- The weight of products through facilities is limited;

-Production at each facility using each manufacturing style is limited;

- Production capacity, inventory storage, and shipping volumes are limited;

- Local content and offset trade are restricted; and

-Credit for duty drawback and duty relief is limited.

To count the number of activities or to inflict fixed charges for activity, we need logical variables along with defining logical constraints:

- Limits on the number of facilities making each product,

- Limits on the number of active facilities by facility type,

- Limits on the number of facilities using each manufacturing style,

- Fixed charges for products made by each facility,

-Fixed charges for facilities making any product, and

- Fixed charges for manufacturing styles used by facilities.

For problems of realistic size and detail, these GSCM features constitute a formidable class of large, difficult optimization models. In particular, the facility fixedcharge features must govern essentially all activities. Also, constraints expressing restrictions on local content and offset trade and those for duty drawback and duty relief essentially couple every individual activity in the entire global supply chain. In fact, the duty constraints require a large number of individual duty coefficients. These duty constraints are exponential in the number of stages, or generations, of the global bill of materials (refer back to Figure 1). However, profitable solutions are distinguished by razor-thin marginsan ideal environment for optimization.

Fortunately, GSCM exhibits special structure, which we have enhanced in the mathematical formulation and exploited with our solver. We invite the user to advise and assist the optimizer by specifying with each constraint just how much it would cost to violate the constraint. Elastic penalties help tell us which constraints are hard (must be respected) and which are soft (may be violated at a penalty cost). Our solver temporarily ignores inconsequential constraints while assembling a good solution and then refines this to an optimal global solution by attending to

\section{Digital needed to reinvent itself, and quickly.}

lesser details. Much of the computational burden would normally be devoted to simply balancing "what goes in, goes out" at each point in the GSCM supply chain. Our solver employs row-factorization, which simplifies these computations. GSCM spans global supply chain generations differing by several orders of magnitude in units and value per unit. Lest the optimizer suffer and thus inflict needless delays on the users, this necessitates scrupulous care in scaling the resulting optimization model and its data. The solver uses branch-andbound enumeration with generalized types of branches. For instance, if we consider opening or closing a facility, we might as well include with the usual fixed charges all the costs pertaining to activities directed 
into or out of the facility. Finally, as we gain experience solving particular types of GSCM models, we keep track of notable successes (and maybe an occasional failure) and build a set of most-successful tuning parameters as we go. All of these features collectively permit the solution of large, difficult instances of the GSCM to optimality or near optimality (Appendices $A$ and $B$ ).

GSCM runs on virtually any computer, from PCs to mainframes.

\section{Impact at Digital}

GSCM is used at Digital by the sourcing and capacity planning (SCP) group within Manufacturing and Logistics. This group performs supply chain analyses on behalf of Manufacturing, Logistics, Services, Acquisition, and various product business units. Teams from the client organizations define the business questions, collect data, perform the supply chain analyses, and present the findings. Each year the SCP group performs a few major, companywide supply chain studies and about 10 single product studies.

Whether for a single product, a portfolio of products, or an entire company, the types of analyses commonly performed are similar:

(1) Find the least-cost supply chain (the most common request);

(2) Find the fastest cycle time (cumulative manufacturing and distribution time per unit) for the supply chain and display the cost / time trade-off curve;

(3) Force the model to use the existing network and compare the resulting cycle time and cost to those of the optimal network;

(4) Swap sources to determine the change in cycle time and cost;

(5) Quantify and rank the impact of duty, freight, labor cost, taxes, and fixed costs to clarify their contributions to total cost;

(6) Quantify the cycle time and cost impact of satisfying an offset-trade or local content requirement;

(7) Experiment with different levels of vertical integration in manufacturing; or

(8) Determine at what volumes second and third sources of supply are warranted.

\section{Categories of Analyses}

Digital uses GSCM for nearly all its studies of supply chain design. These studies fall into three categories:

(1) Analyzing the supply chain for new products,

(2) Analyzing the supply bases for commodities, and

(3) Studying companywide or divisionwide supply chains.

In addition, some companywide studies concern the two-way flow of material: both new products out to the customer and old or defective products back to Digital repair centers.

\section{New Product Pipeline Analyses}

We originally designed GSCM to optimize new product pipelines and by spring 1994 we had done this for about 20 new products (Figure 4 ). We used the early studies to help develop the model and alert management to the impact of supply chain trade-offs. Today, Digital uses the GSCM to resolve single, dual, and triple sourcing questions and to determine which plants and suppliers to employ.

\section{Commodity Supply Base Analysis}

A second type of GSCM application is examining the supply base designs for 


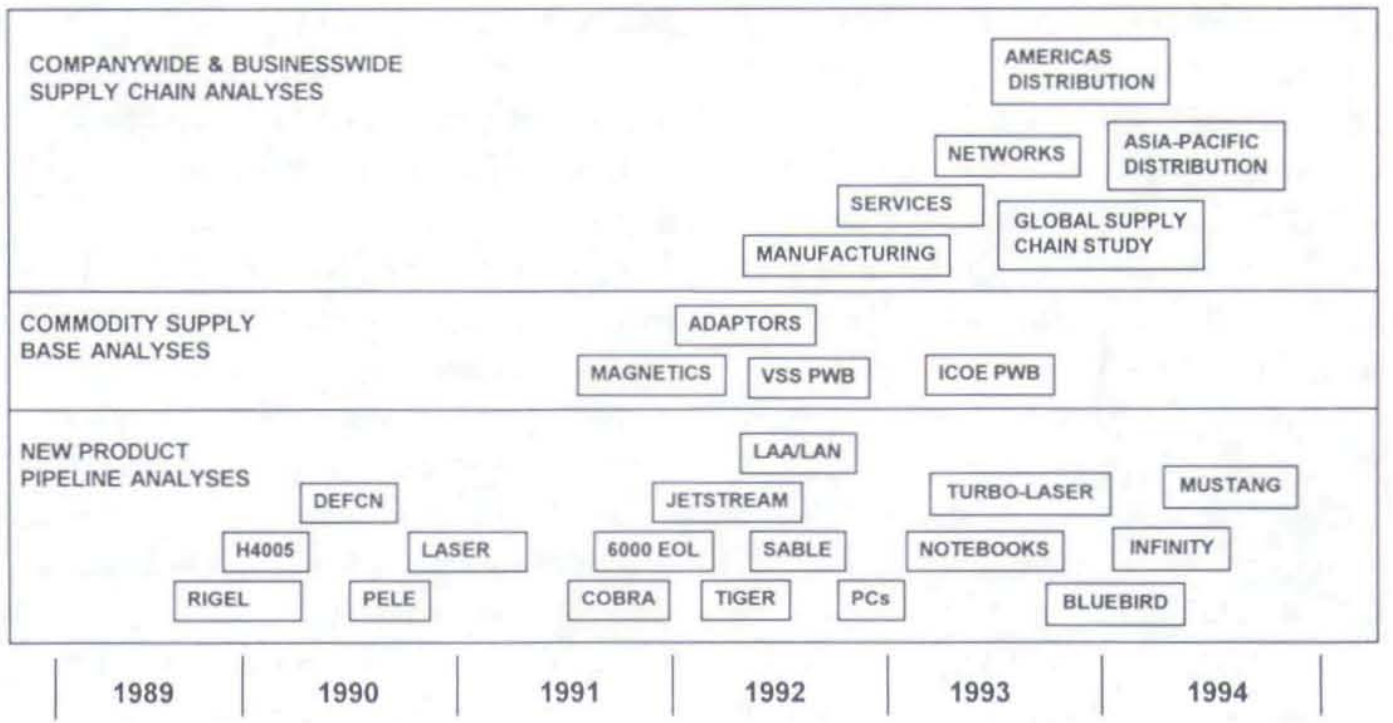

Figure 4: Chronology of GSCM projects at Digital. With growing experience and trust, Digital has increased the number and scope of applications.

commodity products (such as connectors, power supplies and converters, printer wire boards, and semiconductors). Corporate purchasing needs to assign parts to vendors and vendors to plants to achieve competitive cost and cycle times and yet keep the total number of vendors small and manageable. This is challenging in a firm with tens of thousands of parts, many of them uniquely designed for particular products.

GSCM can handle multiple products simultaneously, reducing the vendor base, and rationalizing suppliers geographically.

\section{Companywide or Divisionwide Supply}

\section{Chain Studies}

GSCM is most influential at Digital examining the supply chain for the whole company or for major businesses or divisions. In this kind of study, unlike the first two, there are too many products to include individually. Instead, the problem is aggregated to a manageable size. For some studies (Manufacturing, Services Supply Chain, and America's Distribution), the model is based on styles, or particular methods of manufacturing, repair, and distribution. For example, chip placements and waferboard fabrication are two different examples of manufacturing styles. For other studies such as Networks and Global Supply Chain, we use representative composite products to represent large product families.

Typically, Digital uses the GSCM to first find an optimal solution. Next it tests dozens of alternatives suggested by management. (For example, management might ask for the best possible supply chain that includes a particular plant.) To do this the user fixes part of the supply chain and lets GSCM optimize the remainder. GSCM is typically executed several hundred times during a major study.

In these large companywide modeling efforts, GSCM is one of several parallel anal- 
yses. Examination of various other factors, such as inventory, customer ordering patterns, return on assets, changes in labor costs, and political intangibles often cause the decision makers to adopt a solution that is slightly different from the optimal suggestion from GSCM. However, the GSCM solution is a benchmark for measuring the effects on cost of accommodating these other factors.

GSCM has grown in six years from a small project in distribution to providing the primary analytical foundation for restructuring Digital's supply chain. We describe some of the major studies.

\section{Manufacturing Study}

The manufacturing supply chain study (April to August 1992) determined the optimal supply chain design for all of Digital manufacturing. We built a worldwide model to examine the trade-offs between measures of time (transit time, lead time, manufacturing time), cost, capacity, duty, taxes, and international trade.

The study recommended an 18-month plan to restructure manufacturing infrastructure to reduce costs, reduce assets, and improve customer service. It included worldwide restructuring, rechartering, and tooling changes. The number of plants was to be reduced from 33 to 12 even though company revenues and output would continue to increase (Figure 5). The plan called for the three major customer regions (Pacific Rim, or PACRIM; Americas; and Europe) to be relatively self-contained (that is, served by plants within their own regions). Finally, the recommendation included a quarter-by-quarter implementation plan.

The SCP team estimated that imple- menting the 18-month plan would improve customer satisfaction through better service levels, reduce annual manufacturing costs (nonmaterial spending [NMS], that is, all manufacturing costs except the cost of raw materials and purchased components) by $\$ 225$ million, and reduce logistics cost by $\$ 150$ million.

Management accepted and implemented the 18 -month plan. This resulted in a major consolidation and rechartering of facilities that affected more than half of the company. Manufacture of many products was moved to different locations. To determine the benefits, the study team reviewed the recommendations with the manufacturing controller and his staff to understand how these recommendations were implemented. We then determined which of the benefits (cost savings, asset reduction) could be attributed to the GSCM study. Most of the cost savings are due to lower labor and space requirements and to the increased use of indirect sales channels (outside distributors) for product distribution.

So far (spring 1994) the benefit from this single major study has been that Digital's annual manufacturing costs (NMS) have decreased by $\$ 167$ million and are expected to decrease by another $\$ 160$ million by June 1995. Similarly, to date Digital's annual logistics cost (NMS) has decreased by over $\$ 200$ million even though the number of units manufactured and shipped has increased dramatically.

Many studies of different parts of Digital's supply chain have now been completed. The total benefit to date from all of the restructuring in manufacturing and logistics influenced by the use of the GSCM 

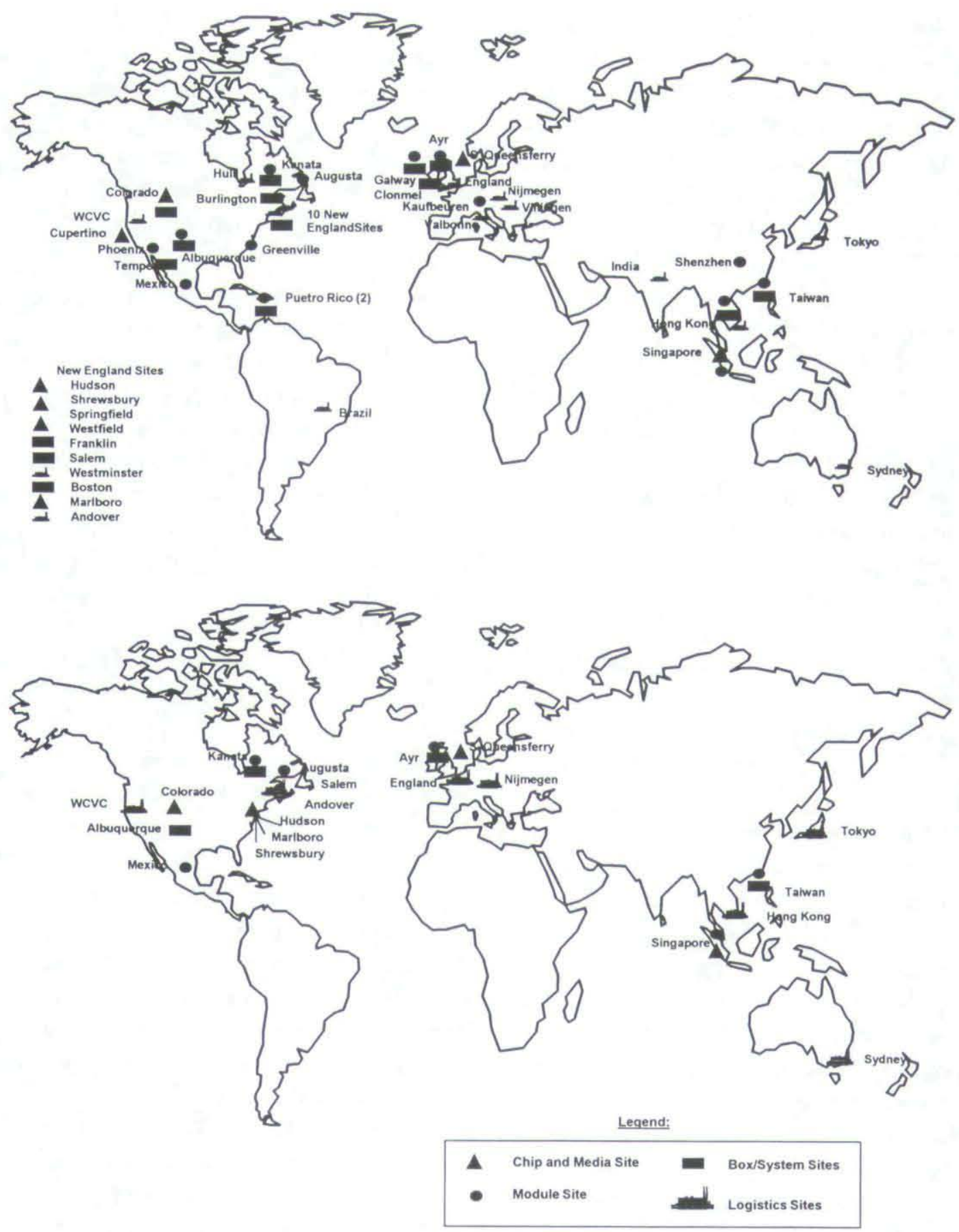

Figure 5: Between 1990 (upper) and 1994 (lower), Digital has used GSCM analyses and recommendations to reduce the number of its facilities by about half, reducing plant and equipment by $\$ 400$ million. Meanwhile, it produces five times as many (smaller) computers and up to 10 times as many disk drives and terminals with fewer people. 


\section{DIGITAL EQUIPMENT CORPORATION}

has been a $\$ 500$ million cost reduction in manufacturing and a $\$ 300$ million cost reduction in logistics as well as a reduction in required assets of over $\$ 400$ million.

\section{Services Supply Chain Study}

The services supply chain study (September 1992 to July 1993) determined the optimal supply chain design for services logistics (the distribution of spare parts and the collection and repair of defective parts) integrated with the manufacturing logistics supply chain. The objective was to determine the number, location, capacity, and service areas for repair centers and parts distribution centers.

This study recommended consolidating the worldwide repair and parts distribution operations into three sites in the Americas, four sites in Europe, and two sites in the PACRIM. It defined the anticipated work load, service areas, and technical capabilities of each site. It also recommended a new, more cost-effective inventory deployment strategy. Management accepted the recommendations and began implementation. Full implementation of the 18 -month plan for services is expected to reduce the number of service facilities from 34 to 17 ; reduce costs by $\$ 81$ million per year; reduce assets by $\$ 34$ million in property, plant, and equipment; reduce inventory by $\$ 74$ million; and improve return on assets for the services business by 7.1 percent.

\section{Networks Study}

The networks business designs and manufactures products for computer networking applications. We conducted this study (August to December 1993) to examine the optimal supply chain design for its set of products. The study confirmed that the current supply chain design for networks is optimal with the exception of some manufacturing that has been relocated to meet offset trade requirements in the PACRIM.

\section{Americas Distribution Study}

We examined (May to December 1993) the best distribution network design for the Americas, looking at the alternatives of shipping directly from plant to customer, an off-the-shelf warehouse approach, and off-site consolidation of customer orders. Our objective was to compare these methods and to determine how many locations are optimal for each and where they should be. The study ranked the list of candidate distribution sites and showed the optimal number of sites, their locations, and the differences in cost and cycle time among alternatives. In addition, management proposed several alternatives. We used GSCM to determine the optimal alternative, which coincided with one of the management proposals. The cost difference between the extremes of the management proposals was $\$ 7.9$ million (about five percent).

\section{Global Supply Chain Study}

The SCP group is currently updating the 18- to 24-month plan and is performing a study of Digital's global supply chain. The study includes all computers, networks, components and peripherals, and storage subsystem products.

\section{Conclusions}

GSCM has played an important role in the reinvention of Digital Equipment Corporation. Scores of studies have been completed based on thousands of optimizations.

Plants and overhead groups are routinely engaged to help develop the 18 - 
month and five-year plans and to make specific sourcing recommendations. GSCM is used daily by the SCP group as they model both large and small pieces of Digital's supply chain. These studies range in scope from divisionwide and worldwide down to supply chain models for specific products or geographies. The comprehensiveness of GSCM in considering a wide range of factors with complete objectivity has provided the analytical means and credibility to stabilize decision making in this most volatile arena.

Digital today consists of 12 plants in seven countries that focus on a reduced set of core competencies. Both the products

\section{Duties can amount to tens of millions of dollars for a large, global company.}

and the supply chain are much simpler. This restructuring has allowed Digital to survive the huge change in the computer industry. Most of the analysis that has been done to guide the restructuring of Digital's physical supply chain has been done with GSCM. Since 1991, Digital has reduced cumulative costs by $\$ 1$ billion and assets by $\$ 400$ million. Meanwhile, unit production is up 500 percent-fewer people are making more product.

From a modeling perspective, GSCM provides some insights. The global bill of materials has been a valuable abstraction for expressing and implementing models of multistage, multilocation fabrication. Before doing this work, we never questioned the wisdom of models that rely on strict level-by-level named echelon structures; now we find such a view awkward. Modeling multiple time periods has provided us with an opportunity to recommend quarter-by-quarter optimal implementation plans, a key advantage in Digital's view. The effects of duty drawback and duty relief interact with many other issues and are subtle but well worth pursuing.

The ability to trade off cost with activity time has been crucial in this fast-paced, competitive industry. Long-term, stationary policies for inventory levels, reordering, batch sizes, or plant loading do not apply very well when the product life cycle is short. Accordingly, GSCM is devoted to quick-response deterministic modeling of global supply chains.

Our solution methods have permitted us to solve large, realistic problems to optimality. This has been critical to Digital management in considering various strategic decisions about the firm's global supply chain.

Lastly, GSCM is a very general approach to modeling supply chains. It is applicable to virtually any firm that is involved in multistage, multiproduct manufacturing. Digital Equipment and Insight, Inc. have been approached by other firms regarding the availability of a tool for managing global supply chains. GSCM is now commercially available, after having been tested and used at another large international firm. As the competitive environment becomes increasingly intense and interconnected and requires deploying resources on a global scale, GSCM provides a powerful means to consider key managerial issues.

Digital has changed, and GSCM has helped it change rapidly and for the better. 


\section{Acknowledgments}

We are grateful for the valuable advice of Rob Dell, Gary Lilien, Tom Magnanti, Mike Olson, Dick Powers, and Kevin Wood.

\section{APPENDIX A: Model Formulation Index Use}

Primary indices and index sets

$p, q \in \mathcal{P}=$ product (part, component, and so forth),

$n \in \mathcal{N}=$ nation,

$f \in \mathcal{F}=$ facility,

$c \in \mathcal{C}=$ customers, and

$t \in \mathcal{T}=$ time period.

Secondary indices

$h \in \mathscr{H}=$ facility type,

$r \in \mathcal{R}=$ manufacturing style (method),

$l \in \mathcal{L}=$ transportation link, and

$m \in \mathcal{M}=$ transportation mode.

Each nation $n$ belongs to a nation group, a collection of one or more nations that permit free trade within the group and charge uniform duties to nations outside the group; for indexing shipping between nation groups:

$o, d=$ origin, destination nation groups

$\{0 \neq d\}$.

A global bill of materials (GBOM) for all finished products shows how each product can be fabricated in multistage manufacturing. At each stage, a more-completed product is assembled from a recipe-a number of units - of each constituent component product. This is a generalization of the classical bill of materials in that we describe all intermediate and final products together, and there may be sourcing options for components that depend upon product, location, and stage of assembly (Figure 1).

The GBOM can be viewed as a collection of rooted arborescences, with each vertex representing a product and the facility that fabricates it. A root vertex represents a finished product and its final fabrication facility, called an ultimate ancestor product. Each level in one of the GBOM arborescences represents a stage of fabrication. An intermediate edge at some level in an arborescence represents assembly of the immediate ancestor, or parent product and facility using its recipe number of units of the component from the immediate descendant, or child product and facility. Parent and child differ by one generation. The ultimate descendant products are leaf vertices. Each vertex has at least one child for each required component, more if there are alternate sourcing opportunities in the supply chain. A product may appear at more than one assembly stage and in more than one arborescence within the GBOM: each appearance must exhibit the same recipe, but not necessarily the same potential sourcing of components, and no product can be its own ancestor. Herein, GBOM vertices are numbered in preorder, also called depth-first-search order, or dynastic order: a root is the first vertex, and vertices are numbered so that all descendants of a vertex are numbered before descendants of any other vertex.

$b \in \mathcal{B}=\mathrm{GBOM}$ entry in preorder and $g \in S=$ generation.

Induced index sets

It is convenient to access sets of products as follows:

$P_{c}=$ products with external demand in

customer $c$ (not restricted to finished products),

$\mathcal{P}_{f}=$ products that can be manufactured at facility $f$,

$\mathcal{P}_{r}=$ products that use manufacturing style $r$, $\mathcal{B}_{p, d}=$ entries in GBOM for product $p$ made by facilities in nation-group $d$, and $p_{b}=$ product at GBOM entry $b$.

A global bill of materials defines partial orders among products $p$ :

$D \mathscr{E} \mathcal{S} \mathcal{N} \mathcal{D} \mathcal{S}_{p}^{\&}=$ descendant products of product $p$ for $g$ generations and

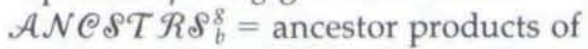
product $p_{b}$ for $g$ generations.

Facilities $f$ are referred to via 
$\mathcal{F}_{p}=$ facilities capable of producing

product $p$,

$\mathcal{F}_{h}=$ facilities of type $h$,

$\mathcal{F}_{r}=$ facilities capable of employing

production style $r$, and

$\mathcal{F}_{n}=$ facilities in nation $n$.

For customers $c$,

$\mathcal{C}_{n}=$ customers in nation $n$.

Manufacturing styles $r$ :

$\mathcal{R}_{f}=$ manufacturing styles available at facility $f$ and

$\mathcal{R}_{p}=$ manufacturing styles possible for product $p$.

Transportation links $l$ :

$\mathcal{L}_{f, *}=$ transportation links originating from facility $f$ (and including $f$ as a destination),

$\mathcal{L}_{*, f}=$ transportation links ending at facility $f$,

$\mathcal{L}_{*, c}=$ transportation links ending at customer $c$,

$\mathcal{L}_{o, d}=$ transportation links between nation groups $o$ and $d$. ( $\mathcal{L}_{o, *}$ represents links between nation-group $o$ and some other nation group.)

For transportation modes $m$

$\boldsymbol{M}_{\boldsymbol{l}}=$ transportation modes available on link $l$.

\section{Data}

(Units shown in parentheses. Product units are either " $p$-units" or " $q$-units," and style units are " $r$-units.")

Production/inventory/shipping

$D E M A N D_{p c t}=$ external demand from customer $c$ for product $p$ (not restricted to finished products) during period $t$ ( $p$-units).

$R E C I P E_{p q}=$ units of child product $q$ required to make one unit of parent product $p$ ( $q$-units $/ p$-unit).

WEIGHT $_{p}=$ weight of product $p$ (weight $/ p$-unit).

$\overline{W E I G H T}_{f t}=$ total throughput limit at facility $f$ in period $t$ (weight).

$S T Y L E_{p f r}=$ amount of style $r$ consumed in the manufacture of product $p$ in facility $f(r$-units $/ p$-unit $)$.

$\overline{S T Y L E}_{f r t}=$ amount of style $r$ available at facility $f$ in period $t$ ( $r$-units).

$\underline{x}_{p f t}, \bar{x}_{p f t}=$ lower, upper bounds on production of product $p$ at facility $f$ in period $t$ ( $p$-units).

$\underline{h_{p f t}}, \bar{h}_{p f t}=$ lower, upper bounds on inventory held of product $p$ at facility $f$ during period $t$ ( $p$-units).

$\underline{S}_{p l m t}, \bar{s}_{p l m t}=$ lower, upper bounds on shipments of product $p$ on link $l$ via mode $m$ in period $t$ ( $p$-units).

System configuration

$\underline{F}_{p}, \bar{F}_{p}=$ lower, upper bounds on number of facilities that may produce product $p$.

$\underline{F}_{h}, \bar{F}_{h}=$ lower, upper bounds on number of facilities of type $h$.

$\underline{F}_{r}, \bar{F}_{r}=$ lower, upper bounds on number of facilities that may use manufacturing style $r$.

Offset trade and local content

$I N C V_{p f t}=$ incremental value added to product $p$ at facility $f$ in period $t$

$(\$ / p$-unit).

$T E V_{n p t}=$ total expected value (computed assuming uniformly-distributed sourcing alternatives throughout the GBOM supply-chain) of product $p$ in nation $n$ in period $t(\$ / p$-unit).

$T E V N_{n}=$ total expected value of product demand in nation $n(\$)$.

$T E V W=$ total expected value of worldwide demand $(\$)$.

$L O C A L_{n t}=$ fraction of local content required by nation $n$ in period $t$.

Duty drawback and duty relief

EXPLODE $_{p q}=$ units of product $q$ required to make one unit of product $p$ ( $q$-units / $p$-unit).

Objective

$\alpha=$ objective weight factor, $0 \leq \alpha \leq 1$, used for convex linear combination of cost and weighted activity time.

$V P C_{p f t}=$ variable cost of producing product $p$ at facility $f$ in period $t(\$ / p$-unit).

$V F C_{p f}=$ variable cost for moving product $p$ through facility $f(\$ /$ weight $)$.

$H C P R O C_{p f t}=$ inventory surcharge for holding the value of unavoidable minimum in-process inventory while produc- 
ing product $p$ at facility $f$ throughout period $t$ ( $\$ / p$-unit).

$H C P I P E_{p f t}=$ pipeline inventory charge for value held in-process while producing product $p$ at facility $f$ throughout period $t$ (\$/p-unit).

$T A X_{p f t}=$ tax on product $p$ at facility $f$ in period $t$ ( $\$ / p$-unit).

$V P C O S T_{p f t}=$ variable production cost, the sum of cost components $V P C_{p f t}, V F C_{p f}$ $\times$ WEIGHT $_{p}, H_{C P R O C}, H C P I P E_{p f t}$, and $T A X_{p f t}$.

$H C_{p f t}=$ cost of holding the value of one unit of inventory of product $p$ at facility $f$ throughout period $t(\$ / p$-unit).

$S H I P C_{l m t}=$ cost to ship on link $l$ via mode $m$ in period $t$ ( $\$ /$ weight).

$\mathrm{HCSHIP}_{\text {plmt }}=$ pipeline inventory charge for value held in-transit while shipping product $p$ on link $l$ via mode $m$ during period $t(\$ / p$-unit $)$.

$D U T Y_{p l t}=$ duty charge for shipping product $p$ on link $l$ during time period $t$ ( $\$ / p$-unit).

$V$ CSHIP $P_{p l m t}=$ variable shipping cost, the sum of cost components SHIPC $C_{\text {lmt }}$ $\times$ WEIGHT $_{p}, \mathrm{HCSHIP}_{\text {plmt }}$, and DUTY $Y_{p l t}$.

$F I X P C_{p f}=$ fixed cost of producing product $p$ at facility $f(\$)$.

FIXFC $_{f}=$ fixed cost of using facility $f$ for any production (\$).

FIXST $_{f r}=$ fixed cost to use style $r$ at facility $f(\$)$.

DUTYA ${ }_{p}^{o, d}=$ duty drawback credit for product $p$ imported into nation-group $d$ from nation-group $o$ and reexported in the same condition ( $\$ / p$-unit).

$D U T Y I_{p}^{o, d}=$ duty drawback credit for product $p$ imported into nation-group $d$ from nation-group $o$ and reexported in a different condition (also called manufacturing drawback) ( $\$ / p$-unit).

DUTYW ${ }_{p}^{o, d}=$ duty relief credit for product $p$ imported into nation-group $d$ from nation-group o containing domestic goods returned in a different condition ( $\$ / p$-unit).

$P D A Y S_{p f t}=$ processing activity days to pro- duce product $p$ at facility $f$ during period $t$ (days / $p$-unit).

$T D A Y S_{p l m t}=$ transit activity days for product $p$ on link $l$ via mode $m$ in period $t$ (days / $p$-unit).

\section{Decision Variables}

Production/inventory / shipping

$x_{p t t}=$ production variables, units of prod-

uct $p$ produced by facility $f$ during period $t$, ( $p$-units) $\forall f, p \in \mathcal{P}_{f}, t$. (This notation suggests an access mechanism for indices of summation.)

$h_{p f t}=$ inventory variables, units of inven-

tory held at facility $f$ of product $p$ at the end of period $t$, ( $p$-units) $\forall f, p \in \mathcal{P}_{f}, t$.

$s_{\text {plmt }}=$ shipping variables, units of product $p$ shipped on link $l$ via mode $m$ during period $t,\left(p\right.$-units) $\forall p, l, m \in \boldsymbol{M}_{l}, t$.

System configuration

$z_{p f}=$ product-made-by-facility indicator variable, 1 if facility $f$ produces product $p$ during any time period (that is, if any $x_{p f t}>0$ for any $\left.t\right) ; 0$ otherwise, $\forall f, p$ $\in \mathcal{P}_{f}$.

$y_{f}=$ production-by-facility indicator variable, 1 if facility $f$ has any production during any time period (that is, if any $x_{p f t}>0$ for any $\left.p, t\right) ; 0$ otherwise, $\forall f$. $v_{f r}=$ style-used-by-facility indicator variable, 1 if style $r$ is used in facility $f ; 0$ otherwise, $\forall f, r \in \mathscr{R}_{f}$.

Duty drawback and duty relief

Define import and export as directed flows into and out of nation-group $d$. Duties for importing products may be offset by exports. Exports of product $p$ can be used to offset import duties paid either to import product $p$ directly or to import descendants of $p$, which are then exported as part of $p$, or to import ancestors of $p$ that already contain $p$.

$a_{p}^{o, d}=$ duty drawback credit variables:

credit for export of product $p$ out of nation-group $d$ as reexport in the same condition to offset the import of product $p$ into nation-group $d$ from nation-group $o$ ( $p$-units) $\forall p, o, d$.

$i_{p q}^{o, d}=$ duty drawback credit variables: credit 
for export of product $p$ out of nationgroup $d$ as reexport in a different condition to offset the import of descendant product $q$ into nation-group $d$ from nation-group o ( $p$-units) $\forall p, q, o, d$. $w_{p q}^{o, d}=$ duty relief credit variables: credit for export of product $p$ out of nation-group $d$ to offset the import of ancestor product $q$ into nation-group $d$ from nation-group $o$ as domestic goods returned in different condition ( $p$-units) $\forall p, q, o, d$.

\section{Formulation}

Subject to

Production/inventory/shipping

$$
\begin{aligned}
& \sum_{t \in \mathcal{L} * m \in \cdot n_{t}} s_{\text {plmt }}=D E M A N D_{p c t} \\
& \forall c, p \in \mathcal{P}_{c}, t . \\
& x_{p f t}+h_{p f(t-1)}=\sum_{t \in \mathcal{L}_{f * m \in M_{t}}} s_{p l m t}+h_{p f t}
\end{aligned}
$$$$
\forall f, p \in \mathcal{P}_{f}, t .
$$$$
x_{p f t}=\sum_{t \in \mathcal{L}, f, m \in M_{i}} R E C I P E_{p q}^{-1} s_{q l m t}
$$$$
\forall f, p \in \mathcal{P}_{f}, q \in \mathcal{D E S C N D} \mathcal{S}_{p}^{1}, t .
$$

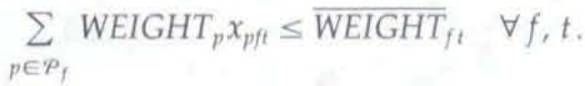$$
\sum_{p \in P_{f}} S T Y L E_{p p r} x_{p f t} \leq \overline{S T Y L E}_{f r t}
$$$$
\forall f, r \in \mathcal{R}_{f}, t .
$$$$
\underline{x}_{p f t} \leq x_{p f t} \leq \bar{x}_{p f t} \forall f, p \in \mathcal{P}_{f}, t ;
$$$$
\underline{h}_{p f t} \leq h_{p f t} \leq \bar{h}_{p f t} \quad \forall f, p \in \mathcal{P}_{f}, t \text {; }
$$$$
\underline{s}_{p l m t} \leq s_{p l m t} \leq \bar{s}_{p l m t} \forall p, l, m \in M_{l}, t .
$$

System configuration

$$
\begin{aligned}
& x_{p f t} \leq \bar{x}_{p f t} z_{p f} \quad \forall f, p \in \mathcal{P}_{f}, t . \\
& z_{p f} \leq y_{f} \quad \forall f, p \in \mathcal{P}_{f} . \\
& \underline{F}_{p} \leq \sum_{f \in \mathcal{F}_{p}} z_{p f} \leq \bar{F}_{p} \quad \forall p . \\
& \underline{F}_{h} \leq \sum_{f \in \mathcal{F}_{h}} y_{f} \leq \bar{F}_{h} \quad \forall h . \\
& \underline{F}_{r} \leq \sum_{f \in \mathcal{F}_{r}} v_{f r} \leq \bar{F}_{r} \quad \forall r .
\end{aligned}
$$

$v_{f r} \in\{0,1\} \forall f, r \in \mathcal{R}_{f}$.

Offset trade and local content

$$
\begin{aligned}
& \left(\sum_{f \in \mathcal{P}_{n, p} \in P_{f, t}} I N C V_{p t t} x_{p t}\right) \\
& \geq\left(\sum_{c \in e_{n, p \in P_{p}, t}} L O C A L_{m t} T E V_{n p t}\right. \\
& \left.\times D E M A N D_{p c t}\right) \quad \forall n \text {. } \\
& \left(\sum_{f \in \mathcal{X}_{m, p} \in P_{f, t}} I N C V_{p f t} x_{p f t}\right) / T E V W \\
& \geq\left(\sum_{c \in e_{n, p \in P_{c}, t}} L O C A L_{n t} T E V_{n p t}\right. \\
& \left.\times D E M A N D_{p c}\right) / T E V N_{n} \quad \forall n .
\end{aligned}
$$

Duty drawback and duty relief

$$
\begin{aligned}
& \sum_{l \in \mathcal{L}_{d, *}, m, t} S_{p l m t} \geq \sum_{o} a_{p}^{o, d} \\
& +\sum_{0, q \in D \delta \delta C N D S p_{p}^{g \mid}} i_{p q}^{o, d} \\
& +\sum_{0, b \in B_{p, d q} \in \mathcal{A N C S T} R s_{b}^{|s|}} w_{p q q}^{o, d} \forall p, d \text {. } \\
& \sum_{l \in \Lambda_{0, d, m, t}} s_{p l m t} \geq a_{p}^{o, d}
\end{aligned}
$$

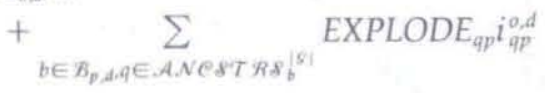

$$
\begin{aligned}
& +\sum_{\left.q \in D \in S C N D S_{p}\right|_{1}} \operatorname{EXPLODE}_{p q}^{-1} w_{q p}^{o, d}
\end{aligned}
$$

$$
\forall p, o, d \text {. }
$$

Objective

$$
\begin{aligned}
& \min \alpha\left[\sum_{p, f, t} V P C O S T_{p f t} x_{p t t}\right. \\
& +\sum_{p f, t} H C_{p f t} h_{p j t} \\
& +\sum_{p, l, m, t} V C S H I P_{p l m t} S_{p l m t} \\
& +\sum_{f, p} F I X P C_{p z_{p f}}
\end{aligned}
$$




$$
\begin{aligned}
& +\sum_{f} \text { FIXFC }_{f} y_{f}+\sum_{f, r} \text { FIXST }_{f r} v_{f r} \\
& -\sum_{p, 0, d} \operatorname{DUTY} A_{p}^{o, d} a_{p}^{o, d} \\
& -\sum_{p, q \in D G s e N D s_{p}^{s !}, 0, d} D U T Y I_{p}^{o, d} i_{p q}^{o, d} \\
& \sum_{p, b \in B_{p, d, q \in \mathcal{A N}} \in S T \pi s_{b}^{(s)}, o, d} \\
& \left.\times \operatorname{DUTYW}_{p}^{o, d} w_{p q}^{o, d}\right] \\
& +(1-\alpha)\left[\sum_{p, f, t} P D A Y S_{p f t} x_{p f t}\right. \\
& \left.+\sum_{p, l, m, t} \operatorname{TDAYS}_{p i m t} S_{p l m !}\right] \text {. }
\end{aligned}
$$

\section{Production / Inventory / Shipping}

Constraints (1) ensure that customer demand ( $p$-units) is met.

Constraints (2) conserve the flow of product ( $p$-units) among production, inventory, and shipping variables.

Constraints (3) express the global bill of materials: production of a parent product ( $p$-units) induces demand for all of its incoming child products ( $q$-units).

Constraints (4) limit total throughput weight for each facility.

Constraints (5) limit the use of a given style ( $r$-units) to its availability, by facility, style, and period.

Constraints (6) are simple bounds on respective production and inventory variables and on the flow over distribution links ( $p$-units).

\section{System Configuration}

Constraints (7) use the production variables and capacities to define the productmade-by-facility indicator variables, which incur a fixed production cost by product by facility.

Constraints (8) use the product-madeby-facility indicator variables to define the production-by-facility indicator variables, which incur a facility fixed charge.

Constraints (9) use the product-made-byfacility indicator variables to control the number of facilities producing each product.

Constraints (10) use the product-madeby-facility indicator variables to limit the number of facilities of each type.

Constraints (11) use the product-madeby-facility indicator variables to limit the number of facilities using each manufacturing style.

Constraints (12) use the production variables and capacities to define the styleused-by-facility indicator variables.

Constraints (13) are respective binary restrictions on the indicator variables for product-made-by, production-by, and style-used-by facility.

\section{Offset Trade and Local Content}

Constraints (14) enforce value-based offset trade restrictions, requiring that the local value added in nation $n$ be at least some minimum fraction of the value sold there.

Constraints (15) are an approximate expression of the country content requirements typical in the US Buy American Act and similar regulations in Europe but more restrictive than the actual legislation. On average, these constraints make every unit of product sold anywhere worldwide satisfy the local content requirements imposed anywhere in the world. That is, if 50 percent minimum US content is imposed, all units produced worldwide will have 50 percent US content; in reality, only the units to be sold to the US government under certain procurement contracts actually need to comply. These constraints are used judiciously for certain situations in the US and Europe where value-based offset trade constraints do not suffice. The mathematical expression states that the local value added in nation $n$, expressed as a fraction of the value of world-wide demand, be at least some fraction of the value sold in nation $n$, expressed as a fraction of the value of demand there.

\section{Duty Drawback and Duty Relief}

Constraints (16) limit the redemption of duty credits to total export of product $p$ 
units out of nation-group $d$. Credits are redeemed either by direct duty drawback for offsetting imports of product $p$ from other nation-groups, or by duty drawback of credits for import of descendant products that are reexported in improved condition in product $p$, or by duty relief of credits for ancestor products imported with product $p$ already contained as components. Tracing of this lineage may be limited in practice to less than $|S|$ generations.

Constraints (17) total imports of product $p$ units into nation-group $d$ from nationgroup $o$ and use this to limit the redemption of duty credits achievable by offsetting exports of product $p$ back to nation-group $o$, either by directly exporting product $p$, or by exporting products containing $p$ or products that will contain $p$.

\section{Objective}

The objective function (18) is a composite of "cost" and "time." The weight factor $\alpha$ is applied to cost terms, such as the variable cost of production, facility throughput costs, and taxes; inventory costs; fixed production costs; and net duty charges. In addition, time-measured in weighted activity days spent in production and in transit—is weighted by $(1-\alpha)$.

\section{APPENDIX B: Solution Methods}

Instances of the mixed-integer linear program GSCM at Digital generally exhibit from 2,000 to 6,000 constraints and 5,000 to 20,000 total variables, with a few hundred of these binary. GSCM is solved at Digital with the X-System [Insight 1990], employing several nontraditional solution methods, including elastic constraints, row factorization, cascaded problem solution, and constraint-branching enumeration.

Elastic constraints may be violated at a given linear penalty cost per unit of violation. Every constraint in GSCM is elastic. For clarity, these penalties are not shown in the mathematical formulation. The XSystem exploits elasticity during optimization, concentrating on the active, or taut, constraints. Setting these elastic penalties warrants some thought: one wants penalties that are meaningful when they are necessary and neither too low (soft) nor too high (hard). Moderation is a virtue. Fast, good-quality solutions are the reward.

Row factorization identifies and exploits sets of constraints which share a common special structure. Brown and Olson [1994] use a 2,171-by-14,518 GSCM example which they call DEC, along with a number of other applications to demonstrate the value of this approach in comparison to the traditional methods used by wellknown commercial optimizers. A third of all the constraints in DEC turn out to have at most one unit-coefficient associated with each variable and thus qualify as generalized upper bounds, while half the constraints have at most two non-zero coefficients associated with each variable and thus qualify as generalized-network rows. Exploiting either of these factorizations reduces the computation time dramatically, especially if factorization isolates many of the taut constraints. In practice, automatic identification of factored constraints in GSCM requires a fraction of a second and isolates more than 80 percent of the taut constraints.

Cascaded problem solutions permit a particularly difficult model to be solved incrementally: a sequence of submodels is solved, subsolutions are analyzed, and records are maintained for the role played by each constraint and each variable, and variables that would otherwise not be part of a submodel are maintained at their lastknown values. Eventually, recorded variable values can be used as an advanced starting point for solving the entire model.

GSCM has been incrementally solved via subproblem cascades defined by labeling constraints and variables as follows: Label system configuration variables and their bounds (13) "0." Label production, inventory, and shipping variables, their bounds (6), and constraints (1)-(4) with 
the associated defining index " $t$." Label style constraints (5) with " $T$," duty drawback and duty relief variables and constraints (16)-(17) with " $T+1$," offset trade and local content constraints (14)(15) with " $T+2$," and finally system configuration constraints (hard, and saved for last) (8) with " $T+3$," (7) with " $T+4$," (9)-(11) with " $T+5$," and (12) with " $T$ +6 ." Next, solve the following sequence of subproblems, where each of these is identified by " (min-label, max-label)": $(0,1),(0,2),(0,3), \ldots,(0, T+6)$.

Constraint branching is a variation of branch-and-bound integer enumeration which selects a branch variable on the basis of its direct influence and the indirect effects of the values it will induce for other structurally dependent variables. For instance, GSCM constraints (8) dictate that if a binary control-variable $y_{f}$ is fixed to zero, then a number of controlled-variables $z_{p f}$ must also be fixed so. One can see that the system-configuration binary variables in GSCM govern essentially the entire problem. Constraint branching speeds up integer enumeration. Branch variables are selected for restriction based on an estimate of the full elastic cost consequences of such restriction. (That is, there is a beneficial interaction between elasticity and constraint branching.)

Model scaling can have a significant effect on solution speed. Sometimes, GSCM users pose problems in units of "each" which would be better stated in millions, or vice versa: Traversal of GBOM paths in such cases can get numerically exciting. An iterative auto-scaling routine in the X-System is employed: About four iterations of scaling by column, and then by row, and so forth, are used to moderate the Frobenius norm (geometric mean) of rows and columns to a more tenable level nearer unity.

Prereduction of model instances prior to optimization, that is, seeking structurally redundant features by evaluating functions with their arguments extremal, can reveal unforeseen curiosities and avoid wasting time solving the wrong models. We prefer that the problem generator be smart enough to detect and unambiguously diagnose data and structural errors in the users' terms before creating a model. After all, the generator knows a lot more about the data and model than the solver does. We use the X-System prereduce function to tell us whether the problem generator is generating "good" models. Our goal is models that cannot be prereduced at all.

Overall, elastic constraints, row factorization, and constraint branching usually suffice to solve GSCM in a minute or so on a personal computer or workstation to within an integrality gap-best incumbent solution cost less lower bound on this cost, expressed as a fraction of incumbent solution cost-of 0.01 percent or better. (Tuning has produced much better performance for GSCM than that reported by Brown and Olson in their experiments with DEC. Cascades are held in reserve for really hard problems.)

However, there are times when this performance is not good enough for Digital. For instance, one solution with an integrality gap reported as 0.00 percent was seen in a visual solution display to be "making some screwy shipments between distant facility pairs when local options are available." Analysis revealed that the criticism was justified: With a scenario system cost of $\$ 5.8$ billion, this $\$ 16$ thousand dollar mistake had slipped through an integrality gap tolerance of only 0.001 percent. Notwithstanding our reasonable arguments for numerical tolerances and realistic expectations, if the user sees compelling visual evidence of error in a solution advertised as optimal, he (or she) loses faith in the entire solution. We have conducted additional research energetically to produce solutions with no integrality gap at all. Today, grudgingly, Digital allows an integrality gap of 0.0005 percent. 
We envy the situation of Breitman and Lucas [1987], whose "managers frequently do not require optimal solutions."

We also wonder how anyone can rely on heuristic solution methods in this arena.

\section{References}

Breitman, Robert L. and Lucas, John M. 1987, "PLANETS: A modeling system for business planning," Interfaces, Vol. 17, No. 1 (January-February), pp. 94-106.

Brooke, A.; Kendrick, D.; and Meeraus, A. 1988, GAMS: A User's Guide, Scientific Press, San Francisco, California.

Brown, Gerald and Olson, Michael 1994, "Dynamic factorization in large-scale optimization models," Mathematical Programming, Vol. 64, pp. 17-51.

Cohen, Morris A. and Lee, Hau L. 1985, "Manufacturing strategy concepts and methods," in The Management of Productivity and Technology in Manufacturing, ed. P. R. Kleindorfer, pp. 153-188.

Cohen, Morris A. and Lee, Hau L. 1988, "Strategic analysis of integrated production-distribution systems: Models and methods," Operations Research, Vol. 36, No. 2 (MarchApril), pp. 216-228.

Cohen, Morris A. and Lee, Hau L. 1989, "Resource deployment analysis of global manufacturing and distribution networks," Journal of Manufacturing and Operations Management, Vol. 2, No. 2, pp. 81-104.

Cohen, Morris A. and Moon, Sangwon 1991, "An integrated plant loading model with economies of scale and scope," European Journal of Operational Research, Vol. 50, No. 3, pp. 266-279.

Cooper, Martha C. and Ellram, Lisa M. 1993, "Characteristics of supply chain management and the implications for purchasing and logistics strategy," The International Journal of Logistics Management, Vol. 4, No. 2, pp. 1324.

Davis, Tom 1993, "Effective supply chain management," Sloan Management Review, Vol. 34, No. 4 (Summer), pp. 35-45.

Dyson, Esther 1992, "Re-creating DEC," Forbes, Vol. 149, No. 7 (March 30), p. 124.

Electronic Business 1992, "DEC's new president sends a message - to management," Vol. 18, No. 14 (November), p. 121.
Geoffrion, Arthur and Graves, Glenn 1974,

"Multicommodity distribution system design by Benders decomposition," Management Science, Vol. 29, No. 5, pp. 822-844.

Geoffrion, Arthur and Powers, Richard 1993, " 20 years of strategic distribution system design: An evolutionary perspective," working paper 431, Western Management Science Institute, University of California, Los Angeles, forthcoming in Interfaces.

Insight, Inc. 1990, " 'X-System,' XS(F) Mathematical Programming System."

Jaffe, Thomas 1993, "DEC on deck," Forbes, Vol. 151, No. 13 (June 21), p. 256.

Thurow, Lester C. 1992, "Who owns the twenty-first century?" Sloan Management Review, Vol. 33, No. 3 (Spring), pp. 5-17.

Jim McCluney, Vice-President of Worldwide Logistics, Digital Equipment Corporation, gave this introduction at the Edelmen Competition on April 24, 1994, Boston, Massachusetts: "The Global Supply Chain Model . . . is a vital part of a supply chain development and of a process reengineering. It's a widely applicable global model. Our Digital team, working with Insight, Inc., began developing in the late 1980's. The team implemented the model in stages, carefully demonstrating its effectiveness one step at a time. The Global Supply Chain Model is a state-of-the-art tool to assist decision making and has transcended all the other models we use. Today it is successfully implemented throughout Digital.

"The sourcing group uses the Global Supply Chain Model daily as it models both large and small pieces of Digital's supply chain . . . the focus can be either on a single product, a portfolio of products, or the entire company. To date, for example, we have used the model to optimize as many as 20 new product introductions ... quantifying and ranking the im- 
pacts of duty, freight, labor costs, taxes, and fixed costs, to understand the contribution to overall total costs. The Global Supply Chain Model has indeed played an enormous role in the reengineering of Digital. . . It's helped us to retool, and invest in new technologies.

"The recommendations . . lead to us reducing manufacturing plants from 33 to 12 with an associated reduction in manufacturing costs, and at the same time we were dramatically expanding our unit output."

Dan Jennings, Vice-President of Worldwide Manufacturing, Digital Equipment Corporation, gave this introduction at the Edelmen Competition on April 24, 1994, Boston, Massachusetts: "Prior to 1991, we were making decisions out of several different structures, several different organizations . . . the unfortunate thing is, they never came together into one decision. We had a large confusion factor.

"Once we had implemented the optimizer, clearly within the manufacturing environment which I'm responsible for, from fiscal year 1992 to the end of fiscal 1993 we have taken out approximately $\$ 500$ million in operating costs and approximately $\$ 1.4$ billion in assets." 
Copyright 1995, by INFORMS, all rights reserved. Copyright of Interfaces is the property of INFORMS: Institute for Operations Research and its content may not be copied or emailed to multiple sites or posted to a listserv without the copyright holder's express written permission. However, users may print, download, or email articles for individual use. 